\title{
P118 Arterial Stiffness in Patients with Arterial Hypertension on Short Term Dual Treatment with Fimasartan/Amlodipine
}

Brandon Giovany Illescas Vidrio*, David Cardona Müller, Ernesto Germán Cardona Muñoz, Claudia Yanette Gálan Ruiz, Carlos Gerardo Ramos Becerra, Fernando Grover Páez

Laboratorio de Mecánica Vascular, Universidad de Guadalajara, Guadalajara, Mexico

\section{ABSTRACT}

Background: Pulse wave velocity (PWV) reflects arterial stiffness and is an independent predictor of cardiovascular mortality and morbidity. It is important to determine the effect dual therapy has on both BP and PWV.

Methods: A quasi-experimental study was performed in patients with grade 1 and 2 primary hypertension (HTN). Patients received the combination amlodipine/fimasartan $(5 \mathrm{mg} / 60 \mathrm{mg} /$ day) for 8 weeks. Anthropometric and hemodynamic measurements were made after a 2-week washout period and at week 8 of treatment. The brachial-ankle pulse wave velocity (baPWV), SBP, DBP, Pulse pressure (PP), central systolic blood pressure (cSBP) and the augmentation index normalized to 75 bpm (pAIx75) were measured.

Results: We included 42 patients (14 women) aged $56 \pm 16$ years. We observed a decrease in baVOP, $17.99 \pm 2.80 \mathrm{~m} / \mathrm{s}$ vs $16.14 \pm 2.36 \mathrm{~m} / \mathrm{s},(p<0.001)$; SBP $160 \pm 18 \mathrm{mmHg}$ vs $138 \pm 14 \mathrm{mmHg}(p<0.001)$; DBP $96 \pm 14 \mathrm{mmHg}$ vs $82 \pm 10 \mathrm{mmHg}$, $(p<0.001)$; PP $63 \pm 18 \mathrm{mmHg}$ vs $56 \pm 14 \mathrm{mmHg},(p<0.001)$; AIx75 $85 \pm 9 \%$ vs $80 \pm 10 \%,(p=0.002)$; and cSBP $151 \pm$ $18 \mathrm{mmHg}$ vs $128 \pm 15 \mathrm{mmHg}(p<0.001)$. Before the treatment $71 \%$ patients had arterial stiffness and after the treatment only $33 \%$ of the patients had it, the BP goal of $<130 / 80$ was achieved in only $16 \%$.

Conclusion: The short term dual therapy with amlodipine/fimasartan significantly decreased baPWV, cSBP, PP, SBP, DBP and pAIx 75 . Only $16 \%$ of the patients achieved the BP goal with this treatment.

\section{REFERENCES}

[1] Munakata M. Brachial-ankle pulse wave velocity: background, method, and clinical evidence. Pulse 2015;3:195-204.

[2] Shi R, Liu K, Shi D, Liu Q, Chen X. Effects of amlodipine and valsartan on blood pressure variability and pulse wave velocity in hypertensive patients. Am J Med Sci 2017;353:6-11.

(c) 2019 Association for Research into Arterial Structure and Physiology. Publishing services by Atlantis Press International B.V. This is an open access article distributed under the CC BY-NC 4.0 license (http://creativecommons.org/licenses/by-nc/4.0/) 